\title{
Elicitin Genes Expressed In Vitro by Certain Tobacco Isolates of Phytophthora parasitica Are Down Regulated During Compatible Interactions
}

\author{
Virginie Colas, Sandrine Conrod, Paul Venard, Harald Keller, Pierre Ricci, and Franck Panabières \\ Unite Santé Végétale et Environnement, Institut National de la Recherche Agronomique, Phytopathologie et \\ Botanique, Villa Thuret, 62 boulevard du Cap, B. P. 2078, 06606 Antibes Cedex, France \\ Accepted 15 November 2000.
}

\begin{abstract}
Phytophthora spp. secrete proteins called elicitins in vitro that can specifically induce hypersensitive response and systemic acquired resistance in tobacco. In Phytophthora parasitica, the causal agent of black shank, most isolates virulent on tobacco are unable to produce elicitins in vitro. Recently, however, a few elicitin-producing $P$. parasitica strains virulent on tobacco have been isolated. We investigated the potential diversity of elicitin genes in $P$. parasitica isolates belonging to different genotypes and with various virulence levels toward tobacco as well as elicitin expression pattern in vitro and in planta. Although elicitins are encoded by a multigene family, parA1 is the main elicitin gene expressed. This gene is highly conserved among isolates, regardless of the elicitin production and virulence levels toward tobacco. Moreover, we show that elicitin-producing $P$. parasitica isolates virulent on tobacco down regulate parA1 expression during compatible interactions, whichever host plant is tested. Conversely, one elicitin-producing $\boldsymbol{P}$. parasitica isolate that is pathogenic on tomato and avirulent on tobacco still expresses parA1 in the compatible interaction. Therefore, some $P$. parasitica isolates may evade tobacco recognition by down regulating parA1 in planta. The in planta down regulation of parA1 may constitute a suitable mechanism for $P$. parasitica to infect tobacco without deleterious consequences for the pathogen.
\end{abstract}

Wild and cultivated plants are in constant contact with many microorganisms yet have developed a number of strategies in order to defend themselves from disease. Indeed, among the range of interactions between plants and pathogens, only a small minority lead to disease development. Plant defense strategies have been divided into two distinct classes (Heath 1981). The most common one, nonhost resistance, implies the existence of preformed physical and chemical barriers and/or the activation of nonspecific plant defense

Corresponding author: F. Panabières; Telephone: +33 493678881 ; Fax: +33 4936 78888; E-mail: panab@antibes.inra.fr

Current address of V. Colas: School of Biological Sciences, Washington Singer Laboratories, University of Exeter, Exeter EX4 4QG, U.K.

Nucleotide sequence of parA1.1 and parA1.2 are in the GenBank database, accession nos. AF316428 and AF316429, respectively. responses triggered upon contact with microorganisms (Heath 1981). Nonhost resistance, which is assumed to be under polygenic control, is therefore not specific because it is effective against all individuals of a given pathogen species. During their evolutionary history, some microorganisms have acquired the pathogenicity factors necessary to infect one or a number of plant species, which then become host plants. These host plants can acquire the ability to protect themselves by specifically recognizing a given pathogen. This second type of resistance, the host-specific resistance, follows the "gene-for-gene concept" (Flor 1971), where the product of a pathogen avirulence gene $(A v r)$ directly or indirectly interacts with a plant resistance gene $(R)$ product in a very specific manner. After recognition, the subsequent steps of the interaction often lead to the hypersensitive reaction (HR) (Goodman and Novacky 1996) and to the activation of plantdefense responses (Hammond-Kosack and Jones 1996). Host resistance, therefore, represents a highly specialized form of interaction because a limited number or only two matching genes are necessary for the recognition event that leads to the subsequent resistance reaction (De Wit 1992).

Host resistance was first demonstrated in pathogen raceplant cultivar interactions. Proteins produced by the phytopathogenic fungus Magnaporthe grisea and the oomycete Phytophthora infestans, however, were shown to act as avirulence factors toward hosts and nonhosts, respectively, at the plantspecies level (Kamoun et al. 1998b; Kamoun et al. 1999; Sweigard et al. 1995). Two kinds of avirulence genes can therefore be defined: cultivar- and species-specific Avr genes (Laugé and De Wit 1998). The fact that pathogen-nonhost interactions may involve species-specific avr genes has led some authors to hypothesize that host and nonhost resistance mechanisms may proceed in the same manner, that is by a recognition between an $A v r$ and a $R$ gene product (Kamoun et al. 1999).

Because there is a growing interest in engineering diseaseresistant plants through the introduction of $R$ and complementary Avr genes in crop plant genomes (De Wit 1992), it remains crucial to investigate how pathogens can overcome the action of naturally occurring resistance mechanisms in plants. These types of studies will undoubtedly help to evaluate the durability potential of artificial resistance.

Resistance and avirulence genes are generally dominant, and disease occurs when one of the genes is absent or defec- 
tive. This has been shown for cultivar- and species-specific Avr genes in plant-fungi interactions. Two single-copy, cultivar-specific $A v r$ genes, for example, have been cloned from Cladosporium fulvum. Named Avr9 and Avr4 (Joosten et al. 1994; Van den Ackerveken et al. 1992), these genes correspond to the $C f-9$ and $C f-4$ tomato resistance genes, respectively (Jones et al. 1994; Thomas et al. 1997). The deletion of Avr9 and single-base-pair changes in the open reading frame (ORF) of Avr4, allow virulent strains to circumvent $C f-9$ - and $C f$-4-mediated resistance of tomato (Joosten et al. 1994; Joosten et al. 1997). The $P W L$ gene family, a group of species-specific $A v r$ genes, has been identified in the blast fungus $M$. grisea. Mutations in $P W L 3$ or incorrect expression of $P W L 4$ appear to confer virulence to $M$. grisea isolates toward weeping lovegrass (Kang et al. 1995).

Tobacco (Nicotiana tabacum) is a nonhost plant species for the devastating plant pathogen genus Phytophthora, except for some Phytophthora parasitica isolates. Phytophthora spp. secrete small proteins called elicitins (Ricci 1997), which are encoded by a small multigene family (Kamoun et al. 1993a; Panabières et al. 1995). Elicitins induce HR and systemic acquired resistance (SAR) in tobacco (Bonnet et al. 1996; Kamoun et al. 1993b; Keller et al. 1996a). Some $P$. parasitica isolates do not secrete elicitins in vitro in detectable amounts, although elicitin genes are present in their genomes (Kamoun et al. 1993a; Ricci et al. 1993). These elicitin-nonproducing $P$. parasitica isolates also are virulent on tobacco. Taken together, the results suggest that elicitins are species-specific avirulence factors toward tobacco (Kamoun et al. 1994; Ricci et al. 1992). P. parasitica, however, is not easily amenable to DNAmediated transformation and, therefore, the role of elicitins in the interaction between this pathogen and its host plant tobacco has not been established clearly. Nevertheless, recent results suggested that INF1, an elicitin produced by $P$. infestans, may govern nonhost resistance of Nicotiana benthamiana to this pathogen (Kamoun et al. 1998b).

The situation became more complex following characterization of $P$. parasitica elicitin-producing isolates that were moderately (Bonnet et al. 1994) or highly virulent on tobacco (Colas et al. 1998). An analysis of the genetic diversity of $P$. parasitica, including elicitin-producing and -nonproducing isolates, provided new insights into the understanding of the molecular events leading to the emergence of $P$. parasitica isolates virulent on tobacco (Colas et al. 1998). Some P. parasitica isolates may be able to circumvent tobacco resistance by losing the ability to secrete elicitins, a type of a loss that may have arisen from rare, independent mutational events because elicitin-nonproducing isolates belong to distinct genotypes. Conversely, the virulence on tobacco of some elicitin-0itin genes leading to proteins that no longer have elicitor activity or from the down regulation of elicitin gene expression in planta.

To test these hypotheses, we focused on the sequences and in vitro and in planta expression of elicitin genes from several $P$. parasitica isolates. In this report, we show that parAl is the main, if not the only, elicitin gene expressed in mycelium grown in vitro and in planta by $P$. parasitica. Furthermore, parAl is highly conserved in $P$. parasitica field isolates collected on various plant species, regardless of their in vitro elicitin production and virulence levels toward tobacco. We present evidence that elicitin-producing isolates pathogenic on tobacco down regulate parAl during compatible interactions, although this down-regulation event does not occur in a $P$. parasitica isolate collected on tomato and avirulent on tobacco.

\section{RESULTS}

\section{Selection of a subset of $P$. parasitica isolates.}

We selected six $P$. parasitica isolates that belong to different genetic backgrounds and are representative of the pathological behavior of this pathogen toward tobacco, in relation to its ability to produce elicitins in vitro. Previously, we have shown that $P$. parasitica isolates fall into three classes (Colas et al. 1998): i) isolates collected on various host plants, except tobacco, all produce elicitins (NTE+) and are avirulent on tobacco; ii) elicitin-nonproducing tobacco isolates (TE-) are highly virulent and specialized to tobacco; iii) elicitinproducing tobacco isolates (TE+) are pathogenic and display a large range of virulence levels on tobacco. Furthermore, TE+ isolates do not appear to be specialized on this host plant. In the present study, carnation 26 and tomato 179 isolates are representative of the NTE+ class. Tobacco isolates 397 and 388 , and 310 and 408 are representative of the TE- and TE+ classes, respectively.

\section{Quantification of elicitin production in vitro.}

Qualitative analysis of elicitin production in vitro has been performed for $P$. parasitica isolates differing in pathogenicity toward tobacco by sodium dodecyl sulfate-polyacrylamide gel electrophoresis (SDS-PAGE) or Western blotting methods (Colas et al. 1998; Kamoun et al. 1994; Ricci et al. 1992). These techniques, however, may not be sufficiently sensitive to assess a possible link between quantitative differences in elicitin production and the variation in virulence levels on tobacco.

Therefore, isolates 26, 179, 310, 408, and 397 were grown in liquid medium for 5 days and the culture filtrates were analyzed for their elicitin content with a double antibody sandwich form of enzyme-linked immunosorbent assay (DASELISA). Elicitin production levels did not differ significantly among elicitin-producing isolates, despite the large variation in their pathogenicity and virulence level on tobacco (Table 1). In addition, a signal was observed in the culture filtrate of the TE- isolate 397, although at a 1,000-fold-lower amount than in the culture filtrates of elicitin-producing isolates. Because the cross reactivity of the sera with heterologous elicitins from various species is known (Devergne et al. 1994), the signals observed in this experiment could have resulted from the expression of variant gene(s) distinct from parAl, encoding protein(s) devoid of elicitor activity on tobacco.

In addition, the very low level of elicitin production observed in the TE- 397 isolate could be the outcome of point mutations, leading to a dramatic decrease of mRNA or protein stability. In view of these possibilities, we analyzed the sequences of elicitin genes actually expressed in several $P$. parasitica isolates.

\section{Sequences of elicitin genes expressed during in vitro growth.}

Total RNA was extracted from the mycelium of several $P$. parasitica isolates grown in vitro and converted into cDNA 
before being used as a template for reverse-transcription polymerase chain reaction (RT-PCR). Oligo(dT) and the degenerate primer uni1 (see below) were used. uni1 defines a region located in the signal peptide of elicitin genes. This region is highly conserved among all genes identified that encode "canonical" elicitins, or ORFs of 98 amino acids primarily identified as biologically active proteins (Kamoun et al. 1993b; Pernollet et al. 1993; Ricci et al. 1989). uni1 has been used previously for the efficient amplification of a large set of elicitin-encoding cDNAs from numerous Phytophthora and Pythium species (Panabières, unpublished results; Panabières et al. 1997; Ponchet et al. 1999). We therefore assumed this would amplify every potentially expressed elicitin gene.

A single fragment of approximately $550 \mathrm{bp}$ was generated in all cases (Fig. 1A). The amplification signal was lower in TE- isolates than in TE+ and NTE+ isolates, which may reflect the relative abundance of mRNA encoding elicitin in the various isolates. The amplification products were purified, cloned, and sequenced.

Five independent clones were sequenced for each of five isolates $(26,310,408,397$, and 388) and compared with parAl genomic sequence (Kamoun et al. 1993a). Among the 25 sequences, two different transcripts were identified that perfectly match the whole coding region of parAl. These were subsequently designated parA1.1 and parA1.2. The parA1.1 and parA1.2 cDNAs differ from parAl only by two mismatches at nucleotides 366 and 385 (Fig. 2). These differences occur within the 3' untranslated region (UTR), and both consist of G-A transitions. Because all clones analyzed exhibited adenine residues at these positions, the parAl allele described by Kamoun et al. (1993a) probably represents a variant of the canonical sequence of the parasiticein gene. parAl.1 and parA1.2 differ from each other by a G-A transition at position 461 in the 3' UTR. One to four out of the five clones analyzed corresponded to one of the two cDNAs for each isolate, except for isolate 26 , where parA1.1 only was detected. Because Phytophthora spp. are diploid organisms, parAl.1 and parA1.2 may correspond either to two parasiticein genes or to two distinct alleles of a single gene.

Sequencing experiments allowed characterization of the first entire 3' UTR for a parasiticein gene to date. The canonical sequence of parAl, extended with the newly determined $3^{\prime}$ UTR, was therefore compared with similar regions of elicitinencoding sequences isolated from Phytophthora or Pythium species (Kamoun et al. 1997; Mao and Tyler 1996; Panabières et al. 1995; Panabières et al. 1997). No significant similarity was found outside the coding region (data not shown), but the overall size and the base composition of the $3^{\prime}$ UTR was close to the UTRs from other elicitin genes. Moreover, a sequence identified as a polyadenylation signal (ATGAA), located $19 \mathrm{bp}$ upstream from the poly(A) tail, was identical to that observed in several elicitin sequences (Panabières et al. 1995; Panabières et al. 1997).

Taken together, these results suggest that parAl is clearly the most highly expressed gene encoding canonical elicitin in $P$. parasitica in mycelium during in vitro growth. Furthermore, although elicitin gene expression could not be detected by Northern blot analyses in TE- isolates (Kamoun et al. 1993a; this study and data not shown), parAl is expressed in these isolates on the basis of RT-PCR. No sequence divergence among the analyzed clones could be observed no matter which pathogenicity toward tobacco and the elicitin gene expression level in vitro of the isolates were selected for this study. Hence, we reasoned that down regulation of parAl mRNA expression in planta could allow certain E+ isolates such as 408 to evade recognition when interacting with tobacco. We therefore studied the expression of parAl during the interaction between $P$. parasitica and tobacco.

\section{parA1 expression during $P$. parasitica-tobacco interaction.}

We originally hypothesized that differences in parAl expression in planta could contribute toward differences in the pathogenicity on tobacco among elicitin-producing $P$. parasitica isolates. To test this hypothesis, a positive control to determine the levels of elicitin gene expression for an isolate with low or null virulence on tobacco was necessary. This type of a control, however, could not be obtained a priori because a nonpathogenic strain would not develop in planta. Consequently, the pathogen biomass would not be sufficient to detect elicitin gene transcription even if it occurs. This biological limitation could, however, be circumvented by using tobacco plants, which would be more susceptible to $P$. parasitica than $N$. tabacum cv. Xanthi. In order to carry out this experiment, we used transgenic Xanthi tobacco plants (NahG8) that were transformed with the nahG gene from Pseudomonas putida, which encodes a salicylate hydroxylase. These transgenic plants no longer accumulate salicylic acid (SA) (Gaffney et al. 1993) and, because SA mediates the induction of SAR in tobacco upon elicitin treatment, NahG8 tobacco plants are more susceptible to elicitin-producing Phytophthora spp. than wild-type plants. There are, however, no differences in susceptibility after infection by TE- $P$. parasitica isolates (Keller et al. 1996b).

Table 1. Biological characteristics of the isolates in this study

\begin{tabular}{|c|c|c|c|c|}
\hline Isolate & Host plant origin & Virulence on tobacco ${ }^{\mathrm{a}}$ & Elicitin production in vitro ${ }^{\mathrm{a}}$ & Elicitin produced in vitro $(\mathrm{ng} / \mathrm{ml} / \mathrm{mg} \text { of dry weight })^{b}$ \\
\hline 26 & Carnation & Null & + & $596.87 \pm 36.60^{\mathrm{d}}$ \\
\hline 179 & Tomato & $\mathrm{Null}^{\mathrm{c}}$ & + & $1137.51 \pm 139.06^{\mathrm{d}}$ \\
\hline 310 & Tobacco & Low & + & $899.81 \pm 155.03^{\mathrm{d}}$ \\
\hline 408 & Tobacco & High & + & $697.16 \pm 43.21^{\mathrm{d}}$ \\
\hline 397 & Tobacco & High & - & $0.66 \pm 0.06^{\mathrm{d}}$ \\
\hline 388 & Tobacco & High & - & Not tested \\
\hline
\end{tabular}

${ }^{a}$ Decapitated stem inoculation was used to measure virulence levels on tobacco. Elicitin production in vitro noted in the fourth column was qualitatively scored by Western blotting. These results have been published previously (Colas et al. 1998).

${ }^{\mathrm{b}}$ In vitro elicitin production was quantitatively measured by double antibody sandwich form of enzyme-linked immunosorbent assay. Values are means \pm standard deviation of three independent replicates.

${ }^{c}$ I. Lacourt and F. Panabières, unpublished results.

d Values with the same symbol do not significantly differ according to student's $t$ at $p=0.05$. 
Zoospores from isolates 26, 310, 408, and 397 were infiltrated into tobacco leaves of Xanthi wild-type NahG8 and NahG9 lines. Disease or resistance symptoms (HR-like necrosis or disease lesion) appeared 3 days after inoculation (Fig. 3 ). Isolate 26 , collected on carnation, induced a HR-like necrosis on all tobacco lines. This result was expected because elicitin-induced necrosis is not SA dependent (Keller et al. 1996b). The susceptibility of NahG8, however, was comparable to that displayed by wild-type or NahG9 plants because no disease developed in the conditions used. Isolates 408 (TE+) and 397 (TE-) both induced disease symptoms on all tobacco lines. No necrosis was observed, even when plants were inoculated with the elicitin-producing isolate 408. Finally, the TE+ isolate 310 did not induce any symptoms of necrosis or

\section{$\begin{array}{llllll}1 & 2 & 3 & 4 & 5 & 6\end{array}$}

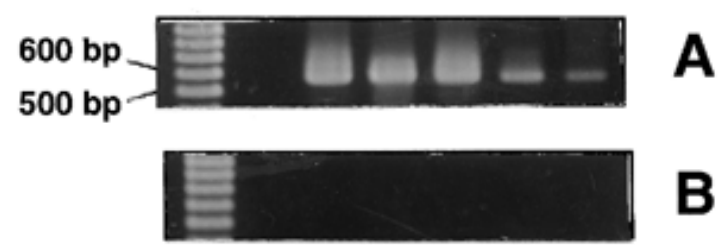

Fig. 1. In vitro expression of elicitin-encoding sequences in various Phytophthora parasitica isolates. Reverse transcription-polymerase chain reaction amplifications were performed on $\mathbf{A}, \mathrm{cDNA}$ or $\mathbf{B}$, total RNA as a control for testing potential amplification of contaminating genomic DNA. The degenerate primer uni1, located in the highly conserved region encoding the signal peptide, was used in combination with oligo(dT). Lane 1, Control (no RNA); lane 2, isolate 26 (NTE+); lane 3, isolate $310(\mathrm{TE}+)$; lane 4 , isolate $408(\mathrm{TE}+)$; lane 5, isolate $397(\mathrm{TE}-)$; lane 6 , isolate 388 (TE-). disease on wild-type and NahG9 plants, whereas an intermediate reaction between necrosis and disease was observed in NahG8 leaves.

Total RNA was extracted from inoculated leaves and hybridized with a $P$. parasitica-specific rDNA probe. Hybridization signals were observed only in the samples from leaves that displayed disease symptoms (Fig. 4A and C). Hence the lack of disease development always correlated with the absence of pathogen growth in planta. On the basis of symptom observations and Northern blot analysis, isolate 310 appears to colonize the leaves of NahG8 lines but not those of NahG9 or wild-type lines.

When parAl-encoding cDNA was used as a probe, in planta parAl expression could not be detected in Northern blot experiments (data not shown). Therefore, the RNA samples were used as templates for RT-PCR experiments in order to investigate in planta expression of the elicitin gene. Amplification products were resolved in agarose gels, blotted, and identified by hybridization with homologous, cloned probes. We used a cDNA encoding cytosolic cyclophilin from $P$. parasitica (cypl) (F. Panabières, unpublished) as a positive control.

The expression time course of cypl broadly followed the results obtained in Northern blots with the $P$. parasitica rDNA probe. A strong signal was obtained from the early stages of disease development, appearing as soon as 1 day after inoculation (Fig. 5B and D). In contrast, cypl appeared on the first day after inoculation of wild-type plants with the incompatible isolates 26 and 310 and was no longer detected at later stages (Fig. 5B). This could reflect the efficient restriction of the pathogen growth once tobacco resistance mechanisms are induced. Surprisingly, the expression of cypl was not detected in the incompatible interaction between isolate 26 and NahG8

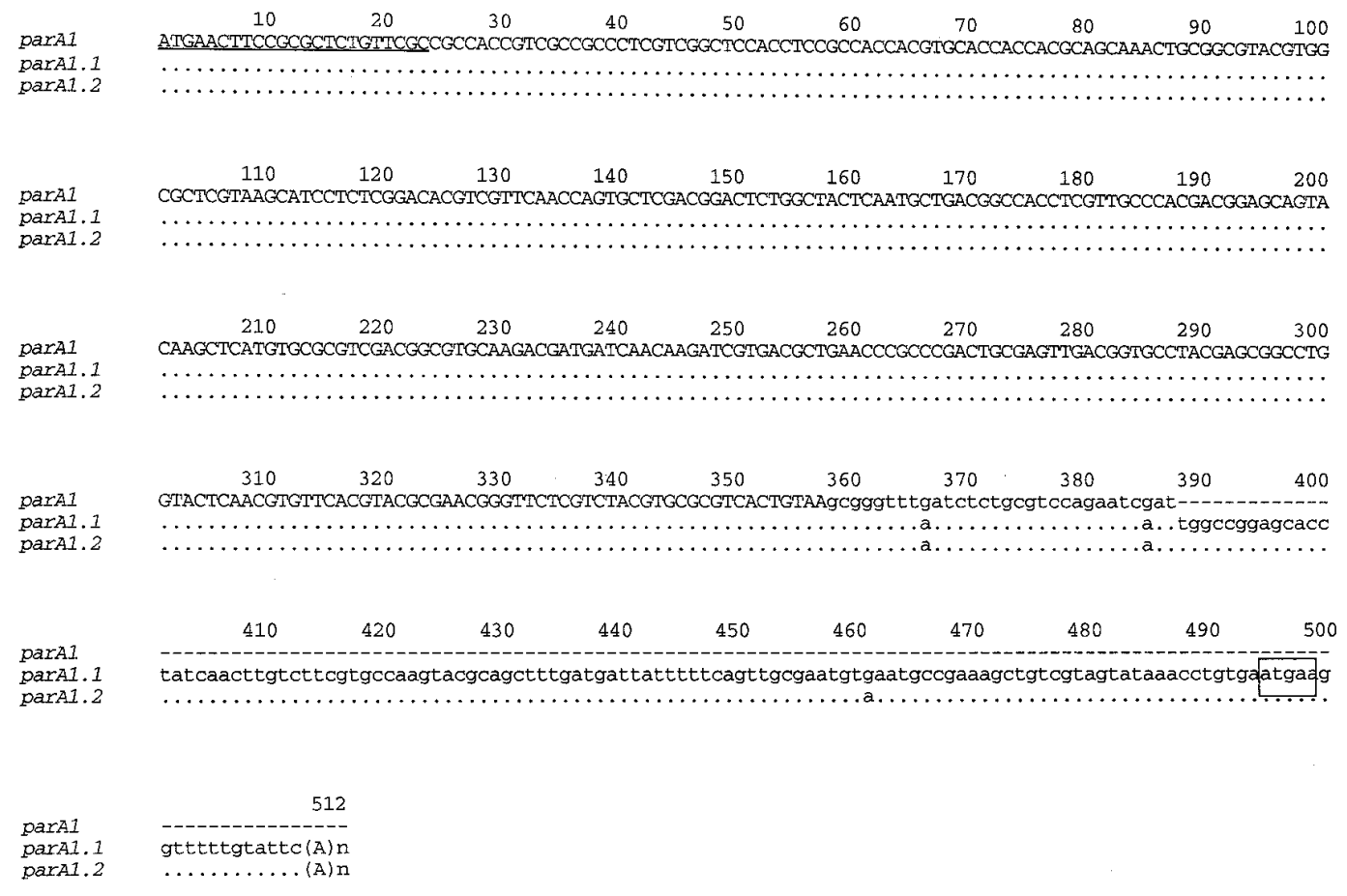

Fig. 2. Sequence alignment of the genomic sequence of parAl (Kamoun et al. 1993) and reverse transcription-polymerase chain reaction (RT-PCR)based elicitin cDNAs (parA1.1 and parA1.2). Coding regions are in capital letters and the putative polyadenylation site is boxed. Underlined sequence corresponds to uni1, the $5^{\prime}$ primer used for RT-PCR amplifications. 
line (Fig. 5D). This can be explained by a poor reproducibility as a result of a critical threshold for the detection of a pathogen transcript during incompatible interactions. Alternatively, because cyclophilin gene expression is induced under various stress conditions and external stimuli in plants such as SA (Marivet et al. 1994), it may be that plant resistance mechanisms in wild-type tobacco lines (which are abolished in transgenic plants) can, to some extent, induce the expression of the $P$. parasitica cypl gene.

Although NTE+ isolate 26 induced a strong necrosis reaction on all tobacco lines, no expression of parAl could be detected at the mRNA level. This is likely to be a result of the low amount of pathogen biomass that hampered efficient detection of pathogen transcripts. The parAl probe did not reveal any signal in samples inoculated with the TE- isolate 397 , as expected. More surprising was the absence of any signal when inoculating plant with TE+ isolate 408, which produces parasiticein in vitro. Conversely, a low level of parAl expression was detected in NahG8 plants inoculated with the weakly virulent TE+ isolate 3103 days after inoculation. This signal was correlated with a faint necrotic symptom. Because both strains developed equally in NahG8 leaves (Fig. 4), we assumed that the absence of detection of parAl transcript in 408-inoculated plants reflects very low levels of elicitin expression. Moreover, this result is consistent with the observed symptoms of faint necrosis in 310-NahG8 interactions and no necrosis in 408-tobacco interactions (Fig. 3). Similar patterns were obtained when hybridizing with either the coding region (data not shown) or the highly specific $3^{\prime}$ UTR probe (Fig. 5), demonstrating that parAl actually is the elicitin gene expressed during $P$. parasitica-tobacco interactions.

Isolates 310 and 26 were shown to produce similar amounts of parasiticein in vitro (Table 1). The differences of necroses induced during interaction (Fig. 3) compared to their in planta development, reflected by rDNA and cypl accumulation (Figs. 4 and 5), strongly suggests that the isolate 26 produces more elicitin in planta than does the isolate 310 . Because the very low biomass of isolate 26 does not hinder the observation of visible symptoms of necrosis, we might expect the in planta expression of parAl to be exceptionally low in the interaction between isolate 310 and tobacco. In order to address whether the low parA1 expression level observed during isolate 310 tobacco interaction is specific for this isolate or if it depends on the interacting host, we studied the expression of parAl in an alternative compatible interaction between $P$. parasitica and tomato.

\section{parAl expression during $P$. parasitica-tomato interaction.}

The TE+ isolate 310 was collected on tobacco, but it can infect tomato (Colas et al. 1998) as well. Tomato leaves (L. esculentum hybrid $63.5 \mathrm{~F}_{1}$ ) were therefore infiltrated with zoospores of 310 . The $P$. parasitica isolate 179 , which is pathogenic on tomato and produces equivalent amounts of parasiticein in vitro (Table 1), was included in the assay as a control. Similar disease symptoms were observed 3 days after inoculation with both strains (not shown). The extent of pathogen growth was evaluated by Northern blots with a $P$. parasitica-specific rDNA probe (not shown) and by RT-PCR amplification of the $P$. parasitica cypl gene (Fig. 6B). The results indicate that 310 and 179 established a compatible interaction with tomato and that the pathogen biomass is equivalent 3 days after inoculation with both isolates.

The expression of elicitin genes was assessed by RT-PCR amplification of parAl, as previously performed in the tobacco- $P$. parasitica interactions. A strong signal was observed 3 days after inoculation with isolate 179 (Fig. 6A). This signal was observed when either the coding sequence or the $3^{\prime}$ UTR

\section{8}
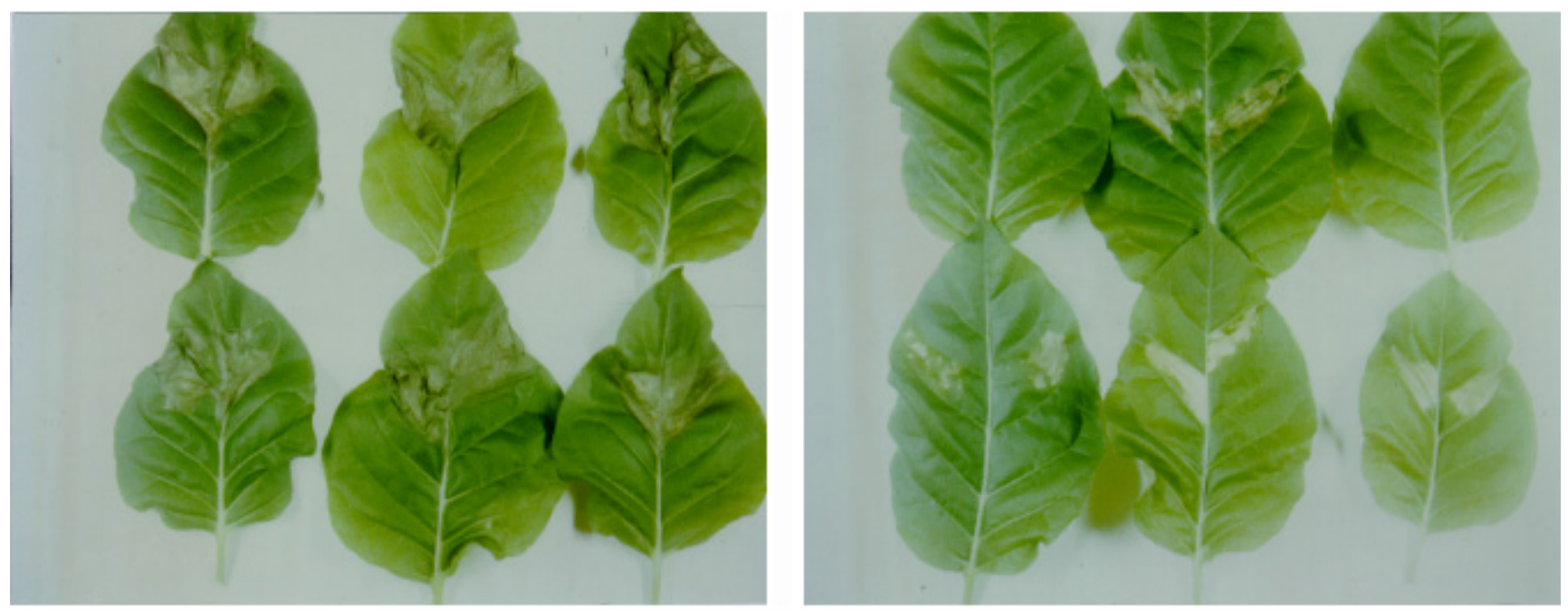

397

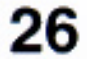

Fig. 3. Tobacco resistance reactions and disease symptoms observed 3 days after leaf infiltration of 200 zoospores of Phytophthora parasitica isolates 26, 310, 408, and 397 in Xanthi wild-type (left) and transgenic tobacco plants expressing (NahG8, center) or not expressing (NahG9, right) the nahG gene. 
of parAl was used as probes. In contrast, no elicitin transcript was detected in tomato leaves inoculated with isolate 310 , although the pathogen clearly demonstrated the ability to develop. We therefore conclude that the down regulation of parasiticein gene expression in planta is a mechanism that is dependent on the $P$. parasitica genotype rather than the host plant.

\section{DISCUSSION}

The absence of parasiticein production by some $P$. parasitica isolates has been shown to be associated with the ability to infect tobacco, whereas production of elicitin has been correlated with low or no virulence on this host plant (Bonnet et al. 1994; Kamoun et al. 1994; Ricci. et al. 1992). Recent analysis of a large collection of $P$. parasitica isolates confirmed this correlation in most cases but also revealed that some isolates highly virulent on tobacco still produced large amounts of elicitin in vitro (Colas et al. 1998). Because elicitins specifically induce defense mechanisms on tobacco, we hypothesized that these isolates might be able to evade tobacco recognition by mutation in elicitin genes or through the regulation of elicitin gene expression. In this paper, we have shown that elicitin-producing isolates virulent on tobacco undergo down regulation of their elicitin genes in planta. This down regulation was observed in tobacco isolates with distinct genetic backgrounds. In contrast, one $P$. parasitica isolate collected on tomato and highly virulent to this host but avirulent on tobacco continues to express elicitin genes during the compatible interaction. Therefore, the down regulation of elicitin gene expression appears to be restricted to isolates that are pathogenic on tobacco.

Sequence analysis and subsequent hybridization with specific probes demonstrated that parAl, as described previously
(Kamoun et al. 1993a), is the main elicitin gene expressed in vitro and in planta by $P$. parasitica.

The mechanisms leading to parAl down regulation may be diverse such as cis-events (point mutations, deletions or insertions in the promoter, and mRNA stability) or on the basis of the action of trans-acting factors (repression or lack of induction). We have shown that parAl is functional in the "nonproducing" isolates of $P$. parasitica, even if expressed at a low rate. Two nearly identical transcripts encoding parAl were identified clearly in all isolates, regardless of elicitin production in vitro. On the basis of this analysis, it would appear that the low levels of parasiticein production do not originate from mutations in the coding and the $3^{\prime}$ UTRs that might affect the stability of the protein or the mRNA. The two parAl transcripts could, perhaps, correspond to either two distinct genes or to two allelic forms of a single parAl gene. Although additional sequencing of promoter regions are required in producing and nonproducing isolates, trans-acting factors are more likely to be at the origin of this low expression than defective promoters for both copies or alleles. In two analyses of independent genetic crosses between one producing and one nonproducing isolate of $P$. parasitica (Colas 1997; Kamoun et al. 1994), the 17-21 and 13-14 progeny, respectively, failed to secrete elicitin in vitro. Despite the small number of progeny in these crosses, the results also favor the hypothesis of trans-acting repressor elements that control elicitin expression. This type of regulatory pathway would be well adapted for this multigene family.

The repression hypothesis could be evaluated with a transformation-based strategy. We recently performed efficient heterologous expression of cryptogein, an elicitin gene from Phytophthora cryptogea, under the control of its own promoter in P. infestans (Panabières et al. 1998). The same ap-

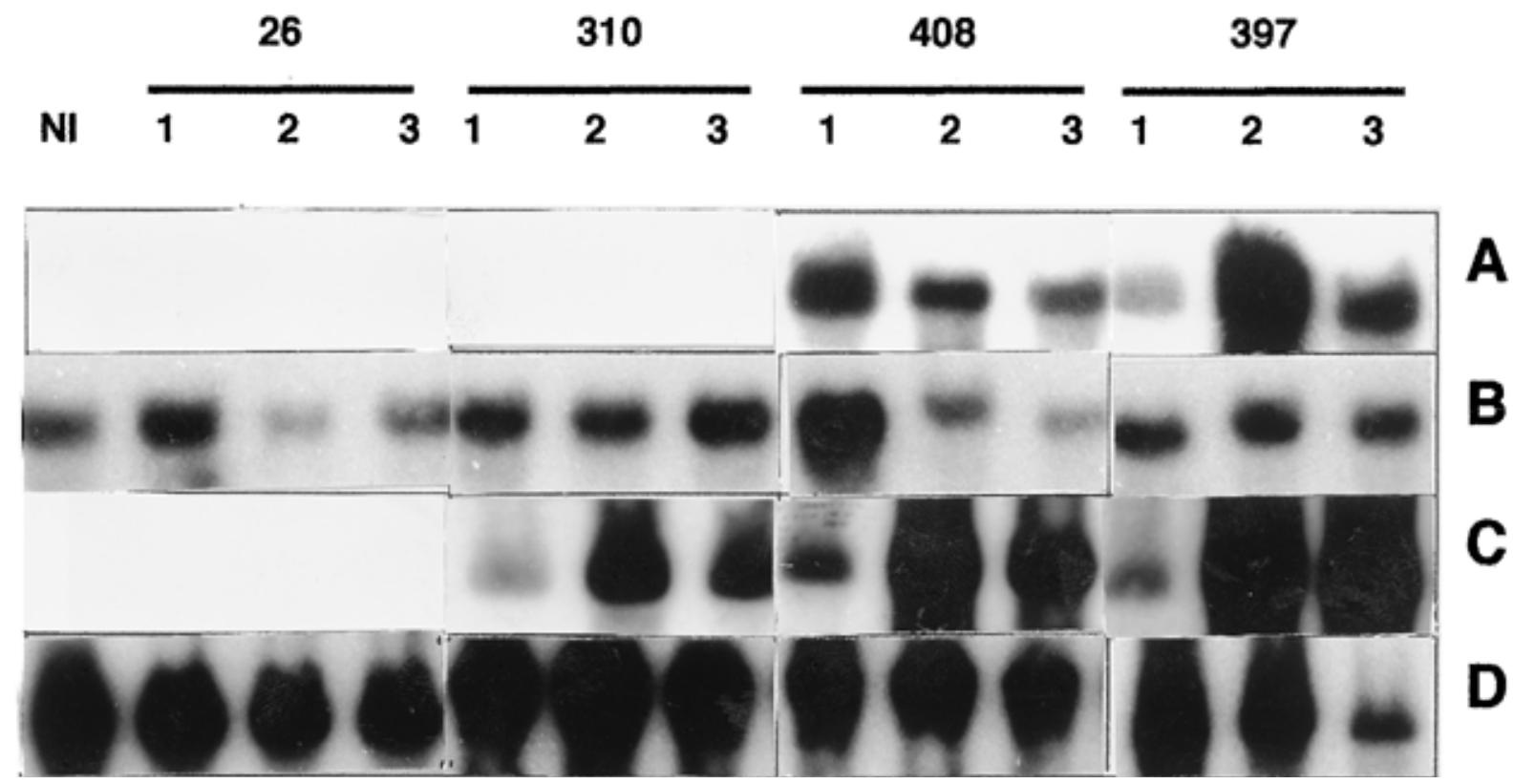

Fig. 4. Development of Phytophthora parasitica isolates 26, 310, 408, and 397 in A and B, wild-type and C and D, NahG8 tobacco plants, as reflected by Northern blot hybridization. Total RNA $(15 \mu \mathrm{g})$ was extracted from infected tobacco leaves 1,2 . and 3 days after inoculation and hybridized with a $P$. parasitica-specific probe derived from 28S rDNA (A and C). To allow normalization for differences in loading samples among lanes, the same blots were stripped and reprobed with a nonspecific probe derived from the 18S rDNA from the root-knot nematode Meloidogyne incognita (B and D). $\mathrm{NI}=$ RNA isolated from noninfected leaves. 
proach with a parAl gene isolated from a nonproducing strain of $P$. parasitica, would either lead to a failure of gene expression, if its promoter is defective, or to production of parasiticein, if parAl is submitted to a trans-repression in its native genetic background. Alternatively, the transformation of a tobacco isolate with the cryptogein gene would permit us to determine whether the trans-repressors, if they exist, act specifically on parAl sequences or other elicitin genes. The recent report of the transformation of a tobacco strain of $P$. parasitica (Bottin et al. 1999) offers the opportunity to test this hypothesis.

Recently, the existence of field isolates of P. infestans, which naturally fail to produce elicitin, has been described (Kamoun et al. 1998a). It would be interesting to develop transformation and genetic cross approaches in order to check whether the lack of elicitin production is mediated by similar mechanisms in $P$. infestans and $P$. parasitica.

For the analysis of elicitin gene expression during in planta growth, we used NahG8 transgenic tobacco plants (Gaffney et al. 1993) because we expected that, in this genetic background, the pathogen biomass would increase as a result of greater susceptibility to $P$. parasitica and, therefore, improve the detection of $P$. parasitica mRNA, even for isolates that are weakly virulent on tobacco. This attempt was successful for the tobacco isolate 310 . The symptoms observed in the present study in wild-type and NahG8 tobacco plants following inoculation by several $P$. parasitica isolates are broadly consistent with those observed previously (Keller et al. 1996b), although slight differences were noted. This is mainly a result of differences in the inoculation methods. We performed leaf infiltrations with zoospores, whereas Keller et al. (1996b) inoculated decapitated stems with mycelial plugs. Stems are more susceptible organs to soilborne Phytophthora spp. than are leaves, whereas tobacco leaves are more responsive to HR-like necrosis induced by elicitins than are stems. In the present study, we selected the zoospore-leaf infiltration assay because it is the most convenient one to study elicitin gene expression during infection, for several reasons. First, plant infections by Phytophthora spp. occur through zoospores in natural conditions (Erwin and Ribeiro 1996). Second, elicitins applied to decapitated tobacco stems translocate rapidly throughout the plant, whereas they remain restricted to the infiltration area when infiltrated into tobacco leaves (Keller et al. 1996a). Consequently, the leaf infiltration method allowed the comparison of disease symptoms and necrosis formation at the same time as elicitin gene expression, precisely at the inoculation site.

The tobacco pathogenic $P$. parasitica isolates 408 and 310 undergo down regulation of parAl mRNA in planta, but are indiscernible from other $P$. parasitica isolates that are nonpathogenic to tobacco with regard to their elicitin gene expression and production levels in vitro. Down regulation (either constitutive or induced during the interaction) might represent an advantage for some $P$. parasitica in order to evade the elicitation of tobacco resistance. This hypothesis is supported by a recent study where $P$. infestans strains deficient for the production of an INF1 elicitin were obtained through an antisense gene-silencing strategy (Kamoun et al. 1998b). Whereas wild-type strains are unable to infect $N$. benthamiana, the pathogenicity of INF1-deficient strains to this nonhost plant is enhanced because 20 to $30 \%$ of inoculations lead to disease development.

The down regulation of elicitin gene expression has been observed in strains isolated from tobacco and virulent to this plant. The in planta down regulation of parAl mRNA for tobacco isolates occurs in compatible interactions with two host plants tested, tobacco and tomato. As tomato does not appear to react to elicitins, the down regulation of parasiticein gene expression by isolate 310 is not required for successful invasion. The parasiticein gene is expressed in the tomato isolate 179 during its interaction with tomato. Therefore, the mechanism of down regulation observed for $\mathrm{E}+$ tobacco isolate 310

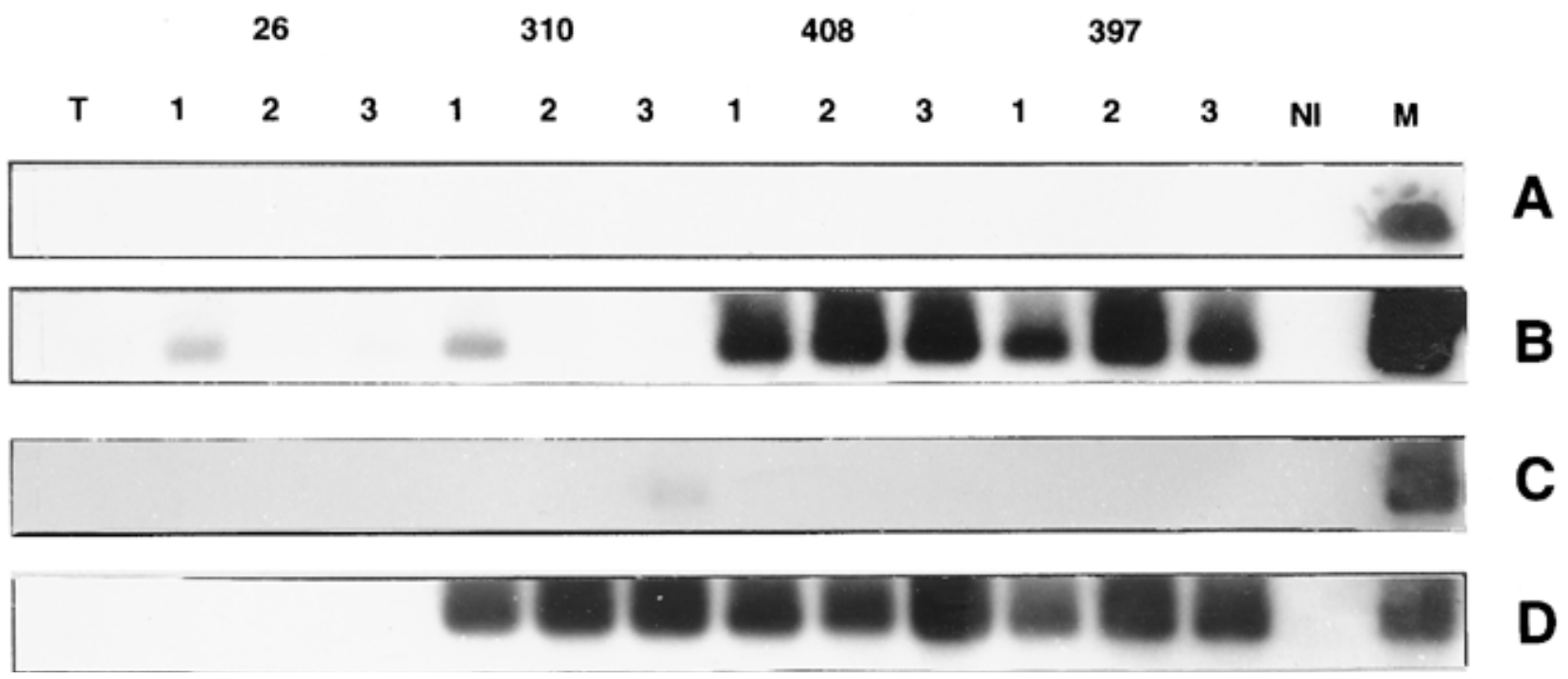

Fig. 5. Time-course expression of parasiticein and cyclophilin genes during the interaction between Phytophthora parasitica isolates 26, 310, 408, and 397 and $\mathbf{A}$ and B, wild-type and $\mathbf{C}$ and $\mathbf{D}$, NahG8 tobacco plants. Reverse transcription-polymerase chain reaction (RT-PCR)-derived amplification products were separated on Tris-borate-EDTA agarose gels, Southern blotted, and hybridized with the parAl 3' untranslated region (A and C) or cyp1 cDNA (B and D) as probes. RNA was isolated after 1, 2, and 3 days after inoculation. T = negative control for RT-PCR amplification (no RNA); $\mathrm{NI}=\mathrm{RNA}$ isolated from noninfected leaves; $\mathrm{M}=$ template RNA isolated from isolate 26 mycelium. 
appears to occur in compatible interactions, regardless of the reactivity of the given host to elicitins. Further experiments are needed to identify the origin of the signal that triggers this down-regulation event.

It should be noted that even when parAl is expressed in planta, its expression is never detected earlier than 3 days after inoculation. It has been reported that infl is not expressed in zoospores nor in germinating cysts of $P$. infestans, whereas it is expressed in the mycelium (Kamoun et al. 1997). Because parAl expression is detected in planta at a late stage, a down regulation of parAl in zoospores and germinating cysts of $P$. parasitica also is likely to occur.

Although avirulence genes restrict the host range of pathogens, they are maintained in natural populations. Therefore, avirulence genes may have pleiotropic intrinsic functions for plant pathogens (Knogge 1996; Laugé and De Wit 1998). The loss of avirulence genes leads to reduced virulence or fitness for several fungal and bacterial pathogens (Kearney and Staskawicz 1990; Laugé et al. 1997; Rohe et al. 1996), which supports this hypothesis. In the case of $P$. parasitica, parAl is highly conserved in field isolates, which suggests that a particularly strong selective pressure acts on this gene. Thus it is tempting to consider that parasiticein possesses an essential, intrinsic function for $P$. parasitica. Recently, elicitins have been shown to be sterol carrier proteins (Mikes et al. 1998). As Phytophthora spp. are auxotrophic for sterols (Hendrix 1970), elicitins probably possess a crucial biological function for these organisms. Down regulation of parAl mRNA in planta may therefore constitute a suitable mechanism to infect tobacco, without deleterious consequences for the pathogen. parAl is, strikingly, highly conserved among $P$. parasitica, even in TE- isolates, which are still able to express it, although at low levels. This indicates that for these isolates, the faint level of elicitin production is sufficient to fulfill its function or that parAl is expressed at higher rates at a different developmental stage that has not yet been characterized.

\section{MATERIALS AND METHODS}

\section{P. parasitica growth conditions.}

$P$. parasitica isolates were obtained from the INRA Antibes collection and were maintained on malt-agar $(1 \%, 1 \%, \mathrm{wt} / \mathrm{vol})$ at $24^{\circ} \mathrm{C}$. For DAS-ELISA experiments and RNA extractions, isolates were grown on a defined liquid medium (Hall et al. 1969).

\section{Quantification of elicitin production in vitro by DAS-ELISA.}

Amounts of elicitin secretion in 5-day-old culture filtrates was quantified by DAS-ELISA, according to Devergne et al. (1994). A monoclonal antibody raised against cryptogein (an elicitin produced by $P$. cryptogea) that cross reacts with parasiticein and a polyclonal antibody raised against parasiticein were used as trapping antibodies. For each ELISA test, a range of dilutions of purified parasiticein were used for construction of a reference dose-response curve.

\section{Infection assays.}

For experiments on elicitin gene expression in planta, $100 \mu \mathrm{l}$ of sterile water solution containing 200 zoospores was infiltrated, as described (Galiana et al. 1997), into leaves of 2month-old untransformed and transgenic tobacco plants (Xanthi) expressing (NahG8) or not expressing (NahG9) the nahG gene (Gaffney et al. 1993; this paper). Tomato plants (Lycopersicon esculentum hybrid $63.5 \mathrm{~F}_{1}$ ) were inoculated, following the same procedure. Plants were grown in a growth chamber at $24^{\circ} \mathrm{C}$, with $16 \mathrm{~h}$ of illumination at $40 \mathrm{mM} \mathrm{m}^{-2}$ per s.

\section{Total RNA extraction and Northern blot experiments.}

Total RNA was extracted from 3-day-old mycelium grown in vitro and from the infiltrated zone of $P$. parasiticainoculated leaves 1 to 3 days after infection, according to Logemann et al. (1987). A subsequent purification step was added in order to remove any contaminating genomic DNA: sodium acetate ( $\mathrm{pH}$ 5.2) was added at a $3 \mathrm{M}$ final concentration. Samples were kept on ice for $3 \mathrm{~h}$, centrifuged at $4^{\circ} \mathrm{C}$ for $20 \mathrm{~min}$, and washed twice with $70 \%$ ethanol. Migration of total RNA $(15 \mu \mathrm{g})$, capillary transfer, probe labeling, and hybridization at $42^{\circ} \mathrm{C}$ were performed according to standard procedures (Sambrook et al. 1989). Filters were washed at high stringency with a final wash at $0.2 \times \mathrm{SSC}(1 \times \mathrm{SSC}$ is 0.15 $\mathrm{M} \mathrm{NaCl}$ plus $0.015 \mathrm{M}$ sodium citrate) and $0.1 \% \mathrm{SDS}$ at $65^{\circ} \mathrm{C}$.

\section{RT-PCR amplification.}

First-strand cDNA was synthesized from 0.5 and $3 \mu \mathrm{g}$ of total RNA extracted from mycelium or infected leaves in $25 \mu \mathrm{l}$ of final volume with $250 \mu \mathrm{M}$ deoxynucleoside triphosphate (dNTP) (each), $1 \mu \mathrm{M}$ oligo(dT) $)_{15}$, and 1 unit of avian myeloblastosis virus reverse transcriptase (Promega, Madison, WI, U.S.A.). For amplification of elicitin cDNAs, the degenerate primer uni1 (5'-ATGAACTTCCGCGCTCTSYTYGC), previously designed for the cloning of several elicitinencoding sequences from various Phytophthora and Pythium species (Panabières et al. 1997), was used in combination with oligo(dT). A probe corresponding to the cytosolic cyclophilin cypl from $P$. parasitica was amplified with a combination of oligo $(\mathrm{dT})_{15}$ and the primer cyp1 (5'-ATGGACGTGGTCAAG GCCATC), designed after characterization of a cyclophilinencoding cDNA from $P$. cryptogea (F. Panabières, unpublished results). Experimental data concerning the design and cloning of cypl are available upon request. PCR amplification of $5 \mu \mathrm{l}$ of first-strand cDNA were carried out in $50 \mu \mathrm{l}$ of final volume containing $250 \mu \mathrm{M}$ dNTP (each), uni1 or cyp1, and oligo $(\mathrm{dT})_{15}$ primers at 0.5 and $1 \mu \mathrm{M}$, respectively, and 1 unit of Taq DNA polymerase (Appligene, Illkirch, France). Reac-

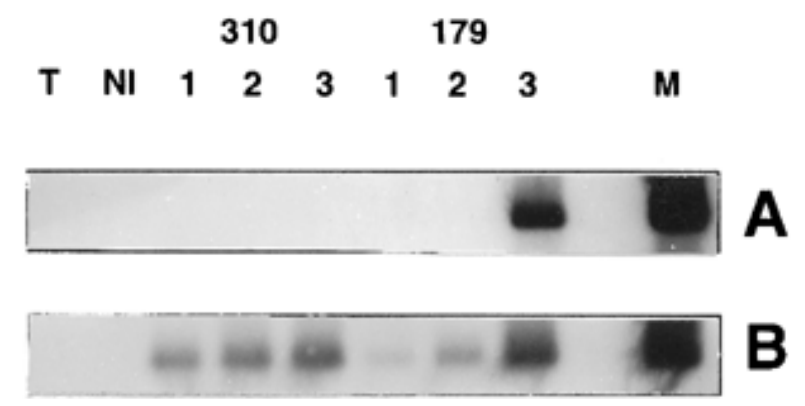

Fig. 6. Time-course expression of A, parAl and $\mathbf{B}$, cypl genes during the compatible interaction between Phytophthora parasitica isolates 310 and 179 and tomato. Analysis of gene expression was performed as described in Figure 5. 
tions were performed with a Robocycler (Stratagene, La Jolla, CA, U.S.A.) for $5 \mathrm{~min}$ at $95^{\circ} \mathrm{C}$ and for 30 cycles of $95^{\circ} \mathrm{C}$ for 1 min, $57^{\circ} \mathrm{C}$ for $1.5 \mathrm{~min}$, and $71^{\circ} \mathrm{C}$ for $1.5 \mathrm{~min}$. A final extension was performed at $71^{\circ} \mathrm{C}$ for $3 \mathrm{~min}$. All RT-PCR experiments were repeated independently at least twice. Purification, cloning, Southern blotting, and hybridization of the RT-PCR amplified products were carried out as described (Sambrook et al. 1989). Southern blots were probed with PCR products encoding the coding sequence and the $3^{\prime}$ UTR of parAl gene, respectively. Hence primers uni1 (see above) and uni2 (5'-CG AGAAGCCGTTCGCGTA) allowed the amplification of the parAl coding sequence, whereas par1 (forward: 5'-GCGGGT TTAATCTCTGCGTCCAGAA) and par2 (reverse: 5'-ATACA AAAACCTTCATTCACAGG) were designed specifically to amplify the 3' UTR of parAl. Sequencing was performed by Genome Express SA (Grenoble, France).

\section{ACKNOWLEDGMENTS}

We gratefully acknowledge C. Barreau (CNRS, Bordeaux, France) and C. Boucher (INRA, Toulouse, France) for fruitful discussions at the beginning of this work, and N. J. Talbot (University of Exeter, U.K.) for critical review of the manuscript. We thank J. Ryals (Paradigm Genetics, Research Triangle Park, NC, U.S.A.) for providing the NahG tobacco lines, and M.-N. Rosso (INRA, Antibes, France) for providing the Meloidogyne incognita 28S rDNA probe.

\section{LITERATURE CITED}

Bonnet, P., Lacourt, I., Venard, P., and Ricci, P. 1994. Diversity in pathogenicity to tobacco and in elicitin production among isolates of Phytophthora parasitica. J. Phytopathol. 141:25-37.

Bonnet, P., Bourdon, E., Ponchet, M., Blein, J. P, and Ricci, P. 1996. Acquired resistance triggered by elicitins in tobacco and other plants. Eur. J. Plant Pathol. 102:181-192.

Bottin, A., Larche, L., Villalba, F., Gaulin, E., Esquerré-Tugayé, M.-T., and Rickauer, M. 1999. Green fluorescent protein (GFP) as gene expression reporter and vital marker for studying development and microbe-plant interaction in the tobacco pathogen Phytophthora parasitica var. nicotianae. FEMS Microbiol. Lett. 176:51-56.

Colas, V. 1997. Recherche des bases moléculaires à l'origine de la spécialisation parasitaire et du pouvoir pathogène dans l'interaction entre Phytophthora parasitica et le tabac. Ph.D. thesis. Paris VI University, France.

Colas, V., Lacourt, I., Ricci, P., Vanlerberghe-Masutti, F., Venard, P., Poupet, A., and Panabières, F. 1998. Diversity of virulence in Phytophthora parasitica on tobacco, as reflected by nuclear RFLPs. Phytopathology 88:205-212.

Devergne, J. C., Fort, M. A., Bonnet, P., Ricci, P., Vergnet, C., Delaunay, T., and Grosclaude, J. 1994. Immunodetection of elicitins from Phytophthora spp. using monoclonal antibodies. Plant Pathol. 43:885896.

De Wit, P. J. G. M. 1992. Molecular characterization of gene-for-gene systems in plant-fungus interactions and the application of avirulence genes in control of plant pathogens. Annu. Rev. Phytopathol. 30:391418.

Erwin, D. C., and Ribeiro, O. K., eds. 1996. Phytophthora Diseases Worldwide. American Phytopathological Society, St. Paul, MN, U.S.A.

Flor, H. H. 1971. The current status of the gene-for-gene concept. Annu. Rev. Phytopathol. 9:275-296.

Gaffney, T., Friedrich, L., Vernooij, B., Negrotto, D., Nye, G., Uknes, S., Ward, E., Kessman, H., and Ryals, J. 1993. Requirement of salicylic acid for the induction of systemic acquired resistance. Science 261:754-756.

Galiana, E., Bonnet, P., Conrod, S., Keller, H., Panabières, F., Ponchet, M., Poupet, A., and Ricci, P. 1997. RNase activity prevents the growth of a fungal pathogen in tobacco leaves and increases upon induction of systemic acquired resistance with elicitin. Plant Physiol.
115:1557-1567.

Goodman, R. N., and Novacky, A. J. 1996. The Hypersensitive Reaction in Plants to Pathogenes: A Resistance Phenomenon, 2nd ed. American Phytopathological Society, St. Paul, MN, U.S.A.

Hall, R., Zentmeyer, G. A., and Erwin, D. C. 1969. Approach to taxonomy of Phytophthora through acrylamide gel-electrophoresis of proteins. Phytopathology 59:770-774.

Hammond-Kosack, K. E., and Jones, J. D. G. 1996. Resistance genedependent plant defense responses. Plant Cell 8:1773-1791.

Heath, M. C. 1981. A generalized concept of host-parasite specificity. Phytopathology 71:1121-1123.

Hendrix, J. W. 1970. Sterols in growth and reproduction of fungi. Annu. Rev. Phytopathol. 8:111-130.

Jones, D. A., Thomas, C. M., Hammond-Kosack, K. E., Balint-Kurti, P., and Jones, J. D. 1994. Isolation of the tomato $C f-9$ gene for resistance to Cladosporium fulvum by transposon tagging. Science 266:789-793.

Joosten, M. H. A. J., Cozinjnsen, T. J., and De Wit, P. J. G. M. 1994. Host resistance to a fungal tomato pathogen lost by a single base-pair change in an avirulence gene. Nature 367:384-386.

Joosten, M. H. A. J., Vogelsang, R., Cozijnsen, T. J., Verberne, M. C., and De Wit, P. J. G. M. 1997. The biotrophic fungus Cladosporium fulvum circumvents $C f$-4-mediated resistance by producing unstable AVR4 elicitors. Plant Cell 9:367-379.

Kamoun, S., Klucher, K. M., Coffey, M. D., and Tyler, B. M. 1993a. A gene encoding a host-specific elicitor protein of Phytophthora parasitica. Mol. Plant-Microbe Interact. 6:573-581.

Kamoun, S., Young, M., Glascock, C. B., and Tyler, B. M. 1993b. Extracellular protein elicitors from Phytophthora: Host-specificity and induction of resistance to bacterial and fungal phytopathogens. Mol. Plant-Microbe Interact. 6:15-25.

Kamoun, S., Young, M., Förster, H., Coffey, M. D., and Tyler, B. M. 1994. Potential role of elicitins in the interaction between Phytophthora species and tobacco. Appl. Environ. Microbiol. 60:15931598.

Kamoun, S., Van West, P., De Jong, A. J., De Groot, K. E., Vleeshouwers, V. G. A. A., and Govers, F. 1997. A gene encoding a protein elicitor of Phytophthora infestans is down-regulated during infection of potato. Mol. Plant-Microbe Interact. 10:13-20.

Kamoun, S., Van der Lee, T., Van den Berg-Velthuis, G., De Groot, K. E., and Govers, F. 1998a. Loss of production of the elicitor protein INF1 in the clonal lineage US-1 of Phytophthora infestans. Phytopathology 88:1315-1323.

Kamoun, S., Van West, P., Vleeshouwers, V. G. A. A., De Groot, K. E., and Govers, F. 1998b. Resistance of Nicotiana benthamiana to Phytophthora infestans is mediated by the recognition of the elicitor protein INF1. Plant Cell 10:1413-1425.

Kamoun, S., Huiteman, E., and Vleeshouwers, V. G. A. A. 1999. Resistance to oomycetes: A general role for hypersensitive response? Trends Plant Sci. 4:196-200.

Kang, S., Sweigard, J. A., and Valent, B. 1995. The $P W L$ host specificity gene family in the blast fungus Magnaporthe grisea. Mol. PlantMicrobe Interact. 8:939-948.

Kearney, B., and Staskawicz, B. J. 1990. Widespread distribution and fitness contribution of Xanthomonas campestris avirulence gene avrBs2. Nature 346:385-386.

Keller, H., Blein, J. P., Bonnet, P., and Ricci, P. 1996a. Physiological and molecular characteristics of elicitin-induced systemic acquired resistance in tobacco. Plant Physiol. 110:365-376.

Keller, H., Bonnet, P., Galiana, E., Pruvot, L., Friedrich, L., Ryals, J., and Ricci, P. 1996b. Salicylic acid mediates elicitin-induced systemic acquired resistance, but not necrosis in tobacco. Mol. Plant-Microbe Interact. 9:696-703.

Knogge, W. 1996. Fungal infections of plants. Plant Cell 8:1711-1722.

Laugé, R., and De Wit, P. J. G. M. 1998. Fungal avirulence genes: Structure and possible functions. Fungal Genet. Biol. 24:285-297.

Laugé, R., Joosten, M. H. A. J., Van den Ackerveken, G. F. J. M., Van den Broek, H. W. J., and De Wit, P. J. G. M. 1997. The in plantaproduced extracellular proteins ECP1 and ECP2 of Cladosporium fulvum are virulence factors. Mol. Plant-Microbe Interact. 10:725-734.

Logemann, J., Schell, J., and Willmitzer, L. 1987. Improved method for the isolation of RNA from plant tissues. Anal. Biochem. 163:16-20

Mao, Y., and Tyler, B. M. 1996. Cloning and sequence analysis of elicitin genes of Phytophthora sojae. Fungal Genet. Biol. 20:169-172.

Marivet, J., Margis-Pinheiro, M., Frendo, P., and Burkard, G. 1994. 
Bean cyclophilin gene expression during plant development and stress conditions. Plant Mol. Biol. 26:1181-1189.

Mikes, V., Milat, M.-L., Ponchet, M., Panabières, F., Ricci, P., and Blein, J.-P. 1998. Elicitins, ptoteinaceous elicitors of plant defense, are a new class of sterol carrier proteins. Biochem. Biophys. Res. Commun. 245:133-139.

Panabières, F., Marais, A., Le Berre, J.-Y., Penot, I., Fournier, D., and Ricci, P. 1995. Characterization of a gene cluster of Phytophthora cryptogea which codes for elicitins, proteins inducing an hypersensitive-like response in tobacco. Mol. Plant-Microbe Interact. 8:9961003.

Panabières, F., Ponchet, M., Allasia, V., Cardin, L. and Ricci, P. 1997. Characterization of border species among Pythiaceae: Several $P y$ thium isolates produce elicitins, typical proteins from Phytophthora spp. Mycol. Res. 101:1459-1468.

Panabières, F., Birch, P. R. J., Unkles, S. E., Ponchet, M., Lacourt, I., Venard, P., Keller, H., Ricci, P., and Duncan, J. M. 1998. Heterologous expression of a basic elicitin from Phytophthora cryptogea in Phytophthora infestans increases its ability to cause leaf necrosis in tobacco. Microbiology 144:3343-3349.

Pernollet, J. C., Sallantin, M., Salle-Tourne, M., and Huet, J. C. 1993. Elicitin isoforms from seven Phytophthora species: Comparison of their physico-chemical properties and toxicity to tobacco and other plant species. Physiol. Mol. Plant Pathol. 42:53-67.

Ponchet, M., Panabières, F., Milat, M.-L., Mikes, V., Montillet, J.-L., Suty, L., Triantaphylides, C., Tyrilly, Y., and Blein, J.-P. 1999. Are elicitins cryptograms in plant-oomycete communications? Curr. Mol. Life Sci. 56:1020-1047.

Ricci, P. 1997. Induction of the hypersensitive response and systemic acquired resistance by fungal proteins: The case of elicitins. Pages 5375 in: Plant-Microbe Interactions. G. Stacey and N. Keen, eds. American Phytopathological Society, St. Paul, MN, U.S.A.

Ricci, P., Bonnet, P., Huet, J. C., Sallantin, M., Beauvais-Cante, F.,
Bruneteau, M., Billard, V., Michel, G., and Pernollet, J. C. 1989. Structure and activity of proteins from pathogenic fungi Phytophthora eliciting necrosis and acquired resistance in tobacco. Eur. J. Biochem. 183:555-563.

Ricci, P., Trentin, F., Bonnet, P., Venard, P., Mouton-Perronnet, F., and Bruneteau, M. 1992. Differential production of parasiticein, an elicitor of necrosis and resistance in tobacco, by isolates of Phytophthora parasitica. Plant Pathol. 41:298-307.

Ricci, P., Panabières, F., Bonnet, P., Maia, N., Ponchet, M., Devergne, J. C., Marais, A., Cardin, L., Milat, M. L., and Blein, J. P. 1993. Proteinaceous elicitors of plant defense responses. Pages 121-135 in: Mechanisms of Plant Defense Responses. B. Fritig and M. Legrand, eds. Kluwer Academic Press, Dordrecht, The Netherlands.

Rohe, M., Gierlich, A., Hermann, H., Hahn, M., Schimdt, B., Rosahl, S., and Knogge, W. 1996. The race specific elicitor, NIP1, from the barley pathogen Rhynchosporium secalis, determines avirulence on host plants of the Rrs1 genotype. EMBO J. 14:4168-4177.

Sambrook, J., Fritsch, E. F., and Maniatis, T. 1989. Molecular Cloning: A Laboratory Manual, 2nd ed. Cold Spring Harbor Laboratory Press, Cold Spring Harbor, NY, U.S.A.

Sweigard, J. A., Caroll, A. M., Kang, S., Farrall, L., Chumley, F. G., and Valent, B. 1995. Identification, cloning, and characterization of $P W L 2$, a gene for host species specificity in the rice blast fungus. Plant Cell.7:1121-1233.

Thomas, C. M., Jones, D. A., Parniske, M., Harrison, K., Balint-Kurti, P., Hatzixanthis, K., and Jones, J. D. 1997. Characterization of the tomato $C f-4$ gene for resistance to Cladosporium fulvum identifies sequences that determine recognitional specificity in $C f-4$ and $C f-9$. Plant Cell 9:2209-2224.

Van den Ackerveken, G. F. J. M., Van Kan, J. A. L., and De Wit, P. J. G. M. 1992. Molecular analysis of the avirulence gene avr 9 of the fungal tomato pathogen Cladosporium fulvum fully supports the gene-forgene hypothesis. Plant J. 2:359-366. 